\title{
Anti-tumor activity of Gastrodia elata Blume is closely associated with a GTP-Ras-dependent pathway
}

\author{
JIN-CHUL HEO ${ }^{1}$, SANG-UK WOO ${ }^{2}$, MINSIK SON ${ }^{2}$, JA-YOUNG PARK ${ }^{2}$, WON-SIK CHOI ${ }^{3,5}$, KYU-TAE CHANG ${ }^{5}$, \\ SUNG-UK KIM $^{5}$, EUN-KYUNG YOON ${ }^{2,4}$, YONG-HOON KIM ${ }^{4}$, HEUNG MOOK SHIN ${ }^{6}$ and SANG-HAN LEE ${ }^{1-3}$ \\ ${ }^{1}$ Food and Bio-industry Research Institute, and Departments of ${ }^{2}$ Food Science and Biotechnology, ${ }^{3}$ Nano-science and \\ Technology, Graduate School, Kyungpook National University; ${ }^{4}$ N\&B Co., Ltd., KNU Business Incubator Center, \\ Daegu 702-701; ${ }^{5}$ Korea Research Institute of Bioscience and Biotechnology (KRIBB), Daejeon 305-333; \\ ${ }^{6}$ College of Oriental Medicine, Dongguk University, Kyungju 780-714, Korea
}

Received March 2, 2007; Accepted May 28, 2007

\begin{abstract}
Gastrodia elata Blume (GEB) is an important medicinal plant in Korea. In order to confirm the anti-tumor activities of GEB extracts, we carried out various in vitro antitumor assays, including a wound assay and an invasion assay using an ethyl ether extract of GEB. The results showed that the GEB extract exhibits potent anti-tumor activity in vitro in a dose-dependent manner. The expression of CD44, cdc42, Timp- 2 or RhoA mRNA did not change by GEB treatment, compared to that of the control. GTP-Ras, an active form of a G-coupled protein family, however, is associated with the anti-tumor activity of GEB extracts. We examined various molecular markers related to metastasis by reverse transcriptase-polymerase chain reaction with the extract of GEB-treated B16 cells. There was an increase in GTP-Ras expression by the Gastrodia elata Blume extract. Together, these results suggest that the Gastrodia elata Blume extract could have potential in alleviating tumorigenesis, by a GTPRas-dependent pathway; although the precise molecular mechanisms are still being examined.
\end{abstract}

\section{Introduction}

Gastrodia elata Blume (GEB) is a traditional herb that has been used in East Asian for centuries. It has been used as an anticonvulsant, analgesic and sedative to combat vertigo,

Correspondence to: Professor Sang-Han Lee, Department of Food Science and Biotechnology, Kyungpook National University, Daegu 702-701, Korea

E-mail: sang@knu.ac.kr

Abbreviations: HUVECs, human umbilical vein endothelial cells; MTT, 3-(4,5-Dimethylthiazol-2-yl)-2,5-diphenyltetrazolium bromide; RT-PCR, reverse transcriptase-polymerase chain reaction; Rho, Ras homologous; GEB, Gastrodia elata Blume

Key words: Gastrodia elata Blume, anti-tumor, GTP-Ras-dependent pathway, B16 melanoma cells hypertension, general paralysis and tetanus. Vanillyl alcohol and gastrodin, derived from GEB are known to have anticonvulsive actions (1). Recently, it was reported that compounds found in GEB inhibited glutamate-induced apoptosis in neuronal cells (2). In addition, after pentylenetetrazole-induced seizure activity, the ether fraction of GEB has been shown to attenuate a decrease in $\gamma$-aminobutyric acid (GABA) and an increase in glutamate content, as well as having anticonvulsant effects (3).

GEB is also used as sub-material for food or food-related industry. In 2001, the Korea Food and Drug Administration approved that GEB extracts as food ingredients; however, an in vivo toxicological study is still needed to determine its safety in food. We have already reported that GEB powersupplemented (0.5-1.0\%) dough had a membrane-like structure that was more developed than that of the control, resulting in increased bread volumes (4). These results suggest that bread baked with $0.5-1.0 \%$ GEB exhibited an increase in loaf volume due to the more complete development of a gluten matrix.

In our study, we determined that GEB protected cell damage by $\beta$-amyloid in neuroblastoma cells (5). The ethyl ether fraction of GEB has potent activity toward $\beta$-amyloidinduced cell damage via reducing caspase- 3 activity $(6,7$; data not shown). In the course of a mechanistic study of the methanolic extract of GEB, we found that it has potent antitumor activity in vitro. The major finding of this report is that GEB exhibits anti-metastatic activities which were confirmed by wound and invasion assay in B16 melanoma cells. We further demonstrated that GEB increased anti-tumor activity via a GTP-Ras-dependent pathway.

\section{Materials and methods}

Cell culture. A murine melanoma cell line B16-F1 (B16; Catalog No. CRL-6323) and human umbilical vein endothelial cells (HUVECs) were obtained from the American Type Culture Collection (ATCC, Manassas, VA). The B16 cells were cultured at $37^{\circ} \mathrm{C}$ in a humidified atmosphere of $5 \% \mathrm{CO}_{2}$ and $95 \%$ air in RPMI-1640 medium supplemented with $10 \%$ FBS, while the HUVECs were cultured in EGM-2 medium 


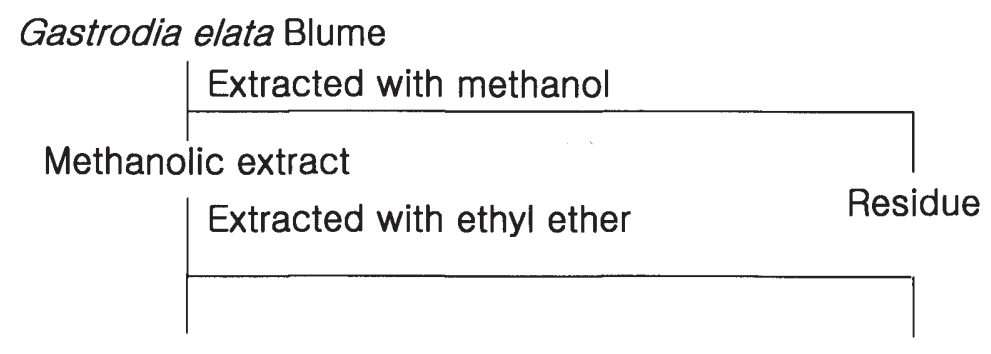

Water layer

\section{Ethyl ether fraction}

Figure 1. A fractionation procedure for the Gastrodia elata Blume extract.

(BD Bioscience, Franklin Lakes, NJ). The B16 cells were maintained in RPMI-1640 medium and subcultured by trypsinization every 3-4 days. The HUVECs were also subcultured every 3-4 days and were used in the experiments.

Chemicals. Matrigel (354234, Beckton-Dickinson, San Jose, CA), and an invasion chamber (3401, Costar, Bethesda, MD) were used for an invasion assay. All other materials were commercially available.

Preparation and fractionation of samples. Three-year-old rhizoma of Gastrodia elata Blume were obtained from a Gastrodia Farm in Youngyang, Kyoungbuk province, Korea. The washed and chopped pieces of GEB were deep-frozen $\left(-70^{\circ} \mathrm{C}\right)$ until use. Freeze-dried GEB was powdered with a homogenizer. GEB was extracted with methanol, and the methanol extract was resuspended in ethyl ether. The fraction was divided into an ethyl ether fraction and a water fraction. Each fraction was evaporated at $30^{\circ} \mathrm{C}$ under reduced pressure (Fig. 1). The color of the fraction was light to dark brown. The plant used in this experiment was collected between June and October, 2005 and was identified by senior staff of the Department of Biology, Kyungpook National University, Daegu, Korea. Voucher specimens of the plant have been deposited in Enzyme Biotechnology Lab., KNU under the accession No. 2005-02.

MTT assay. A MTT assay was carried out as follows: cells $\left(5 \times 10^{5}\right.$ cells $\left./ \mathrm{ml}\right)$ were split in $96-$ well plates and incubated for $24 \mathrm{~h}$ in $100-\mu \mathrm{l}$ of RPMI medium. Various concentrations of extracts were added, and the cells were incubated for an additional $48 \mathrm{~h}$. Then, $10 \mu \mathrm{l}$ of MTT solution $(5 \mathrm{mg} / \mathrm{ml}$ MTT in PBS) was added to each well and incubated at $37^{\circ} \mathrm{C}$ for $4 \mathrm{~h}$. In order to stop the reaction, $100 \mu \mathrm{l}$ of $0.04 \mathrm{M}$ of $\mathrm{HCl}$, in isopropanol, was added with vigorous mixing. The absorbance was determined by a multilabel counter (Victor3; Wallac, Turku, Finland) at 564 nm (8).

Wound healing assay. Strips of thin tape $(2 \mathrm{~mm} \times 2 \mathrm{~cm} ; 3 \mathrm{M}$, Seoul, Korea) were attached to the bottom of each well of the 6-well plates (Greiner, Frickenhausen, Germany), and B16 cells were plated at $1 \times 10^{7}$ cells/well and allowed to attach at $37^{\circ} \mathrm{C}$ for $3-5 \mathrm{~h}$ in a $5 \% \mathrm{CO}_{2}$ atmosphere. The tape strips were then removed, creating linear wounds. The plates were photographed and incubated, as above, with media containing various concentrations of GEB. The plates were photographed at 16, 24 and $40 \mathrm{~h}$ and the exact wound width was calculated by a microruler (http://www.eeob.iastate.edu/faculty/DrewsC/ htdocs/microruler-links.htm) (9).

Invasion assay. Transwell plates (pore size $8 \mu \mathrm{m}$; Costar) were loaded with $100 \mu 1$ of Matrigel (BD Biosciences), which was allowed to solidify for $2 \mathrm{~h}$ at $37^{\circ} \mathrm{C}$, and then the plates were coated with $10 \mu \mathrm{l}$ of fibronectin $(200 \mu \mathrm{g} / \mathrm{ml}$; BD Biosciences). The plates were loaded with B16 cells suspended in a $10 \%$ FBS $\left(1 \times 10^{5}\right.$ cells/well $)$, the samples were exposed to GEB extracts, and the plates were incubated for $24 \mathrm{~h}$ in $5 \% \mathrm{CO}_{2}$ at $37^{\circ} \mathrm{C}$. The migrated cells were fixed with methanol, stained with hematoxylin, and counted under an inverted microscope (Nikon, Tokyo, Japan) (10).

Tube formation assay. HUVECs $\left(2 \times 10^{4}\right.$ cells/well) were dispensed into Matrigel-coated 24-well plates (BecktonDickinson) in $0.5 \mathrm{ml}$ of EGM-2 medium containing various concentrations of GEB extracts, and the cells were incubated for $24 \mathrm{~h}$. The cells were then visualized by microscopy and tube formation was scored by counting the number of tubes formed (11).

RNA isolation and reverse transcriptase polymerase chain reaction. RNA isolation and reverse transcriptase polymerase chain reaction (RT-PCR) were carried out, as described previously, with slight modifications (12-15). Briefly, the total cellular RNA was extracted from B16 cells using the TRIzol reagent (Gibco BRL, Grand Island, NY). First-strand cDNA was synthesized from $1 \mu \mathrm{g}$ of total-RNA using oligo(dT) reverse transcriptase (iNtRON Biotechnology, Sungnam, Korea), and a PCR amplified with specific primers for mice CD44 (forward, 5'-TCG ATT AGA ATG TAA CCT GCC-3'; reverse, 5'-TGG TGT GTT CTA TAC TCG CCC-3'), Paxillin (forward, 5'-ACT ACT GCA ACG GAC CCA TC-3'; reverse, 5'-TCG TGG TAG TGG ACC TCA CA-3'), CDC42 (forward, 5'-TTG TTG GTG ATG GTG CTG TT-3'; reverse, 5'-CCC AAC AAG CAA GAA AGG AG-3'), Timp-2 (forward, 5'GCA TCA CCC AGA AGA AGA GC-3'; reverse, 5'-GGG TCC TCG ATG TCA AGA AA-3'), c-Src (forward, 5'-GCA GCT GTA TGC TGT GGT GT -3'; reverse, 5'-TCA GCA GAA TCC CAA AGG AC-3') and GAPDH (forward 5'-ATG TTC CAG TAT GAC TCC AC-3'; reverse, 5'-GCC AAA GTT GTC ATG GAT GA-3') as an internal control. The resulting PCR products were analyzed by agarose gel electrophoresis and visualized by ethidium bromide staining. 
(A)

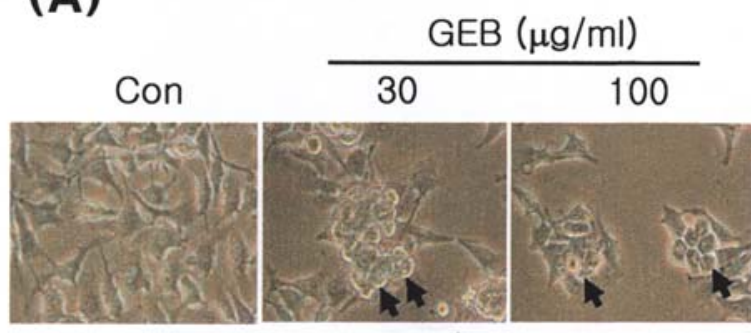

(B)

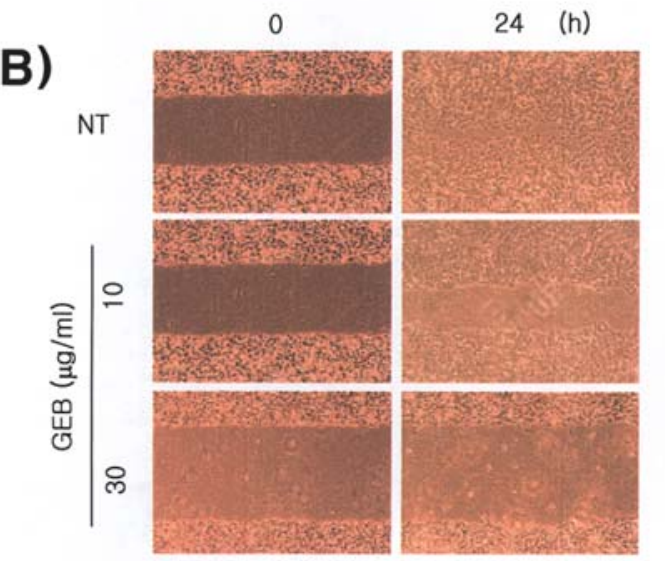

(c)
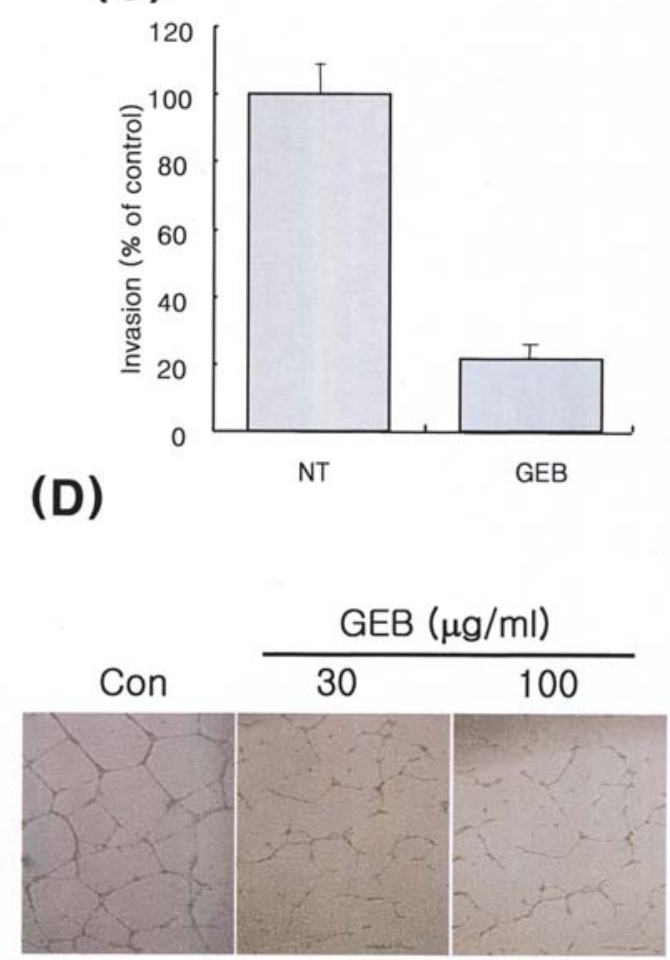

Figure 2. Gastrodia elata Blume exhibits potent anti-tumor activity. (A) MTT assay of the GEB extract. Arrows show the GEB-damaged cells (black arrows) when treated with GEB in a dose-dependent manner. (B) Wound healing assay. Confluent monolayers of B16 cells were pretreated with or without 30 or $100 \mu \mathrm{g} / \mathrm{ml}$ of GEB extract. The monolayers were then wounded and stimulated with $75 \mathrm{nM}$ PMA or left untreated NT. The plates were photographed 0,24 and $48 \mathrm{~h}$ post-wounding. (C) Invasion assay. Cell invasion was assayed in Matrigel-coated Transwell chambers. Invasion was compared among B16 cells exposed to GEB extracts. Cell migration was quantified $24 \mathrm{~h}$ after the cells were exposed to GEB extracts. Migrated cells were counted from five randomly selected microscopic fields, and the results are given as the average per field \pm SD of 3 independent experiments. (D) Tube formation assay. HUVECs were plated at $2 \times 10^{4}$ cells/well in Matrigel-coated 24-well plates, and then exposed to 0,30 or $100 \mu \mathrm{g} / \mathrm{ml}$ GEB extract. After $24 \mathrm{~h}$, the culture supernatants were removed and the cells were fixed with $10 \%$ formalin. Representative results are given of 3 independent experiments.

Western blot analysis. Ras activity was measured using a GTP-Ras Kit (Pierce, Rockford, IL), according to the slight modifications of the manufacturer's instructions. Briefly, B16 cells $\left(1 \times 10^{6}\right.$ cells $)$ were centrifuged at $16,000 \times \mathrm{g}$, and the supernatant was incubated at $4^{\circ} \mathrm{C}$ for $1 \mathrm{~h}$ with the provided GST-Rhotekin-RBD, before loading ( $25 \mu 1 /$ lane) onto a SwellGel immobilized glutathione disk (Pierce). Thereafter, the glutathione disk-bound proteins were solubilized with $2 \mathrm{X}$ SDS [125 mM of Tris-HCl, pH 6.8, 2\% glycerol, 4\% SDS $(\mathrm{w} / \mathrm{v}), 0.05 \%$ mercaptoethanol, and $0.05 \%$ bromophenol blue], eluted from the disk, resolved by $12 \%$ SDS-PAGE and transferred to nitrocellulose membranes (Schleicher \& Schuell GmbH, Dassel, Germany). The membranes, which were blocked for $1 \mathrm{~h}$ with a Tween $(0.1 \%) / \mathrm{TBS}$, were incubated with the primary antibody (Pierce) and then incubated with HRP-conjugated secondary antibody (Pierce). This was done in order to visualize bands by using the ECL detection system (Amersham Pharmacia, Buckinghamshire, UK) $(10,11)$.

Statistical analysis. Data were expressed as the means \pm standard deviation of the mean values. Statistical significance was determined by Student-Newman-Keuls method for independent means, using the Sigma Plot program. The critical level for significance was set at $\mathrm{P}<0.05$.

\section{Results and Discussion}

In this study, we examined whether Gastrodia elata Blume (GEB) inhibited cancer cell growth in vitro. GEB is a traditional medicinal herb which has been used in East Asian countries for centuries. GEB has been used as an anticonvulsant, analgesic and sedative against vertigo, hypertension, general paralysis and tetanus. Recently, it was reported that fractions of this herb inhibited glutamate-induced apoptosis in neuronal cells (2). Moreover, the herb can protect amyloid $\beta$-peptide-induced cell damage in neuroblastoma cells $(5,6)$. GEB has been strongly advocated as a supplement, its extracts can be used as food sub-ingredient; however, an in vivo toxicological study is still needed to verify its biosafety. With a dose between $6 \mathrm{~g} / 60 \mathrm{~kg} /$ day, the in vivo toxicity of GEB did not affect any morphological changes in tissue level (data not shown). It has been determined that GEB extracts exhibited potent anti-oxidant activity $(1,18)$.

On the other hand, cancer progression/metastasis is a complex sequence of events whereby tumor cells invade adjacent tissue (19). The cells penetrate into lymphatics or blood vessels, are transported to near or distant sites and finally, become lodged, extravasate or proliferate in order to form metastatic lesions. The process can cause major complications in chemotherapeutic treatment. Clinical 


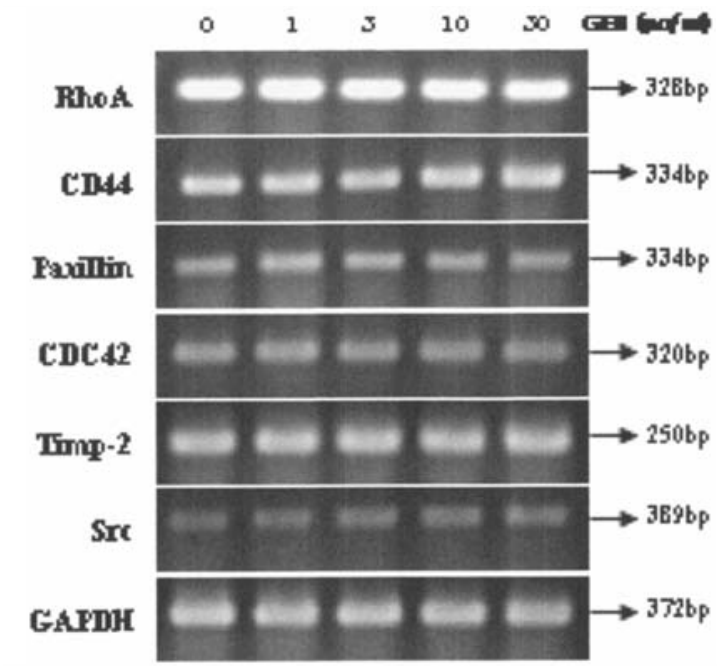

Figure 3. The mRNA expression profile of various molecular targets, by RT-PCR, with or without Gastrodia elata Blume extracts. Data of each primer sequence are shown in Materials and Methods.

oncologists have discovered various molecular markers such as CD44, a uterine plasminogen activator receptor (uPAR), ICAM, VCAM, and matrix metalloproteinases (MMPs) during the progression of cancer (20). In order to improve cancer treatment, a greater understanding of the progression of cancer and/or the metastatic process at the molecular and cellular levels is required.

Therefore, in order to examine the inhibitory effects of GEB in B16 cells, we carried out wound healing and invasion assays to test its in vitro effects on cell migration, which is an important facet of cell motility, particularly in relation to cancer. A wound healing assay revealed that GEB exhibited clear inhibitory wound width, whereas the untreated control showed dense cell growth between wound regions, suggesting that GEB inhibited cell migration in vitro (Fig. 2B). Our invasion assay demonstrated that GEB inhibited invasive activity by $>75 \%$ versus the control group (Fig. 2C). Collectively, these results indicate that GEB inhibited the wound healing of B16 cells and suppressed invasion in vitro in a dose-dependent manner (Fig. 2C and D).

Next, we examined the effects of GEB on angiogenesis, which is a pivotal process of metastasis. HUVECs were treated with GEB, and tube formation was assessed in terms of tube size and numbers (Fig. 2D). Our results revealed that GEB dose-dependently inhibited HUVEC tube formation in vitro at $0-100 \mu \mathrm{g} / \mathrm{ml}$ (Fig. 2D). The control showed the highest levels of proliferation, indicating that endothelial cell growth was not restricted by contact inhibition under our experimental conditions (data not shown). Collectively, these findings indicated that GEB inhibited cell migration, cell invasion and tube formation, in vitro, in a dose-dependent manner. This suggests that the fraction of GEB might function as an antitumor component, in vivo, by decreasing metastasis and angiogenesis.

We investigated the effects of GEB on the levels of its potential signaling partners, Rho GTPases. Signal transduction during invasion or angiogenesis is fairly well-documented. Many transcription factors (e.g., EST-1, c-fos and c-jun) and

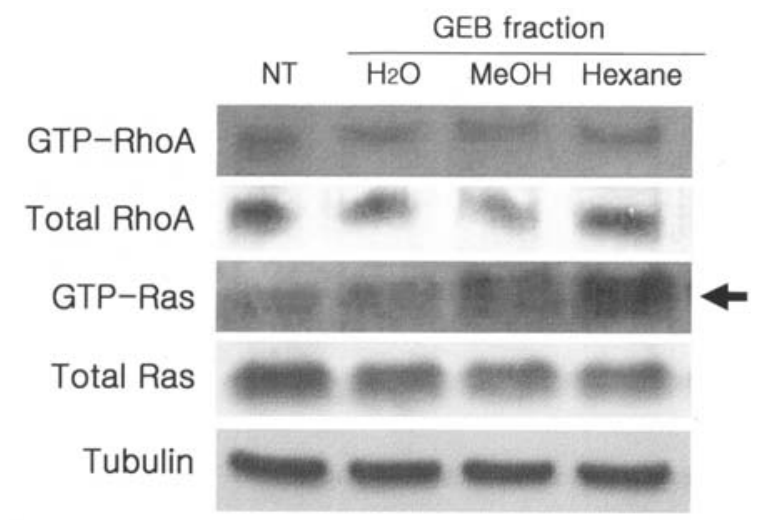

Figure 4. The involvement of the increased GTP-Ras expression by Gastrodia elata Blume treatment. Each lane was loaded with $30 \mu \mathrm{g}$ of GEB-treated cell lysates and the lanes were transblotted to primary antibody in order to detect expressed protein levels.

migration-related proteins are associated with gene expression in endothelial cells during angiogenesis $(21,22)$. VEGF acts as a central regulator, while many morphological changes are overseen by members of the Rho protein family of GTPases. The Rho GTPases such as RhoA, Ras, Rac1, and cdc42, are localized at cell membranes and become activated upon the stimulation of cell-surface receptors (23). The association/ dissociation of GTP to Rho protein families triggers specific cellular responses by mediating cell contractility and organizing actin filaments into stress fibers, which thereby influence the motility and migration of endothelial cells, as well as the formation of new blood vessels.

We compared the mRNA levels of the GEB extracts in order to confirm which molecular mechanisms are involved in B16 cell inhibition. In Fig. 3, we showed that the mRNA expression of the GEB treatment operated in a dose-dependent fashion (0-30 $\mu \mathrm{g} / \mathrm{ml})$. RhoA, Paxillin, CD44, cdc42, Timp-2 or c-Src did not show changed expression levels by GEB. Further investigation regarding the precise molecular mechanism is still needed.

We also examined the effects of GEB on GTP-Ras levels in B16 cells. Our Western blot analysis revealed that the treatment of cells with GEB water, or ethyl ether $(30 \mu \mathrm{g} / \mathrm{ml})$ increased GTP-Ras activity to approximately 90, 250\%, respectively (Fig. 4, arrow), suggesting that GEB had potential in increasing the active forms of Ras rather than the activity level per se.

In conclusion, we demonstrated that GEB extracts inhibited B16 cell growth via a GTP-Ras expression-dependent mechanism, which was confirmed by comparing the Ras-homologous GTPases using Western blotting. If we can control B16 growth suppression by regulating the clinical molecular marker(s), the precise anti-tumor mechanism could be proven, in that the molecular marker(s) could be regulated by the hit(s), including that of GEB extracts.

\section{Acknowledgements}

This study was supported in part by a grant of Oriental Medicine R\&D Project, Ministry of Health \& Welfare, Republic of Korea (HMP-B050042). 


\section{References}

1. Hsieh CL, Chang CH, Chiang SY, Li TC, Tang NY, Pon CZ, Hsieh CT and Lin JG: Anticonvulsive and free radical scavenging activities of vanillyl alcohol in ferric chlorideinduced epileptic seizures in Sprague-Dawley rats. Life Sci 67: $1185-1195,2000$

2. Lee YS, Ha JH, Yong CS, Lee DU, Huh K, Kang YS, Lee SH, Jung MW and Kim JA: Inhibitory effects of constituents of Gastrodia elata B1. on glutamate-induced apoptosis in IMR-32 human neuroblastoma cells. Arch Pharm Res 22: 404-409, 1999.

3. An SJ, Park SK, Hwang IK, Choi SY, Kim SK, Kwon OS, Jung SJ, Baek NI, Lee HY, Won MH and Kang TC: Gastrodin decreases immunoreactivities of $\beta$-aminobutyric acid shunt enzymes in the hippocampus of seizure-sensitive gerbils. J Neurosci Res 71: 534-543, 2003.

4. Kim HJ, Morita N, Lee SH and Moon KD: Scanning electron microscopic observations of dough and bread supplemented with Gastrodia elata Blume powder. Food Res Int 36: 387-397, 2003.

5. Kim HJ, Moon KD, Lee DS and Lee S-H: Ethyl ether fraction of Gastrodia elata Blume protects amyloid B-peptide induced cell death. J Ethnopharmacol 84: 95-98, 2003.

6. Huang NK, Lin YL, Cheng JJ and Lai WL: Gastrodia elata prevents rat pheochromocytoma cells from serum-deprived apoptosis: the role of the MAPK family. Life Sci 75: 1649-1657, 2004.

7. Iuvone T, De Filippis D, Esposito G, D'Amico A and Izzo AA: The spice sage and its active ingredient rosmarinic acid protect PC12 cells from amyloid-beta peptide-induced neurotoxicity. J Pharmacol Exp Ther 317: 1143-1149, 2006.

8. Kratzke RA and Kramer BS: Evaluation of in vitro chemosensitivity using human lung cancer cell lines. J Cell Biochem Suppl 24: 160-164, 1996.

9. Moon SH, Heo JC, Fine RL, Kim HM, Kim SU, Yoon BD and Lee SH: BRD-glucan exhibits potent immunochemotherapeutic activity in vitro and in vivo. Int J Oncol 26: 395-404, 2005.

10. Heo JC, Park JY, Lee JM, Kwon TK, Kim SU, Chung SK and Lee SH: Wisteria floribunda gall extract inhibits cell migration in mouse B16F1 melanoma cells by regulating CD44 expression and GTP-RhoA activity. J Ethnopharmacol 102: 10-14, 2005.

11. Heo JC, Park JY, Woo SU, Lee MS, Rho JR, Lee HJ, Kim SU, Kho YH and Lee SH: Dykellic acid inhibits cell migration and tube formation by RhoA-GTP expression. Biol Pharm Bull 29: 2256-2259, 2006.
12. O'Driscoll L, Daly C, Saleh M and Clynes M: The use of reverse transcriptase-polymerase chain reaction (RT-PCR) to investigate specific gene expression in multidrug-resistant cells. Cytotechnology 12: 289-314, 1993.

13. Yokoyama S and Yamaue H: Prediction of distant metastasis by using reverse transcriptase-polymerase chain reaction for epithelial and variant CD44 mRNA in the peripheral blood of patients with colorectal cancer. Arch Surg 137: 1069-1073, 2002.

14. Tsai WC, Hsu CC, Chen CP, Chen MJ, Lin MS and Pang JH: Ibuprofen inhibition of tendon cell migration and down-regulation of paxillin expression. J Orthop Res 24: 551-558, 2006.

15. Deroanne CF, Hamelryckx D, Ho TT, Lambert CA, Catroux P, Lapiere CM and Nusgens BV: Cdc42 down-regulates MMP-1 expression by inhibiting the ERK1/2 pathway. J Cell Sci 118: 1173-1183, 2005.

16. Ikema K, Matsumoto K, Inomata $\mathrm{Y}$, Komohara $\mathrm{Y}$, Miyajima S, Takeya $\mathrm{M}$ and Tanihara $\mathrm{H}$ : Induction of matrix metalloproteinases (MMPs) and tissue inhibitors of MMPs correlates with outcome of acute experimental pseudomonal keratitis. Exp Eye Res 83: 1396-1404, 2006.

17. Kuo L, Chang HC, Leu TH, Maa MC and Hung WC: Src oncogene activates MMP-2 expression via the ERK/Sp1 pathway. J Cell Phys 207: 729-734, 2006.

18. Yu SJ, Kim JR, Lee CK, Han JE, Lee JH, Kim HS, Hong JH and Kang SG: Gastrodia elata Blume and an active component, p-hydroxybenzyl alcohol reduce focal ischemic brain injury through anti-oxidant related gene expressions. Biol Pharm Bull 28: 1016-1020, 2005.

19. Fidler IJ: The pathogenesis of cancer metastasis: the 'seed and soil' hypothesis revisited. Nat Rev Cancer 3: 453-458, 2003.

20. Kuramitsu Y and Nakamura K: Proteomic analysis of cancer tissues: shedding light on carcinogenesis and possible biomarkers. Proteomics 6: 5650-5661, 2006.

21. Oikawa T and Yamada T: Molecular biology of the Ets family of transcription factors. Gene 303: 11-34, 2003.

22. Haura EB, Turkson J and Jove R: Mechanisms of disease: insights into the emerging role of signal transducers and activators of transcription in cancer. Nat Clin Prac Oncol 2: 315-324, 2005.

23. Buongiorno P and Bapat B: Rho GTPases and cancer. Prog Mol Subcell Biol 40: 29-53, 2005. 